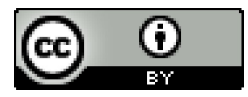

Esta obra está sob o direito de Licença Creative Commons Atribuição 4.0 Internacional.

\title{
VALOR NUTRICIONAL E POTENCIAL DE UTILIZAÇÃO DO RESÍDUO DA INDÚSTRIA DE ALIMENTOS PARA MONOGÁSTRICOS
}

\author{
Rosa Cavalcante Liral \\ Thales José de Lima Belém ${ }^{2}$ \\ Alany Cristyane Felix da Silva ${ }^{3}$ \\ Aliny Cristyna Felix da Silva ${ }^{4}$ \\ Paulo Vanderlei Ferreira ${ }^{5}$ \\ Elton Lima Santos ${ }^{6}$ \\ Sofia Pessoa Lira Souza ${ }^{7}$ \\ José Edmar de Lira ${ }^{8}$
}

\section{RESUMO}

A indústria alimentícia gera uma expressiva quantidade de resíduos, os quais preocupam os órgãos fiscalizadores quanto ao destino final desses resíduos, que, comumente, são depositados no meio ambiente e causam problemas ambientais diversos. Esta revisão tem por objetivo informar o valor nutricional e potencial de utilização do resíduo da semente de maracujá e de biscoito na alimentação de monogástricos. Trata-se de uma revisão de literatura tradicional, não sistemática, de caráter exploratório e qualitativo. Fez-se necessária leitura, análise e interpretação de livros, periódicos, anais de eventos científicos, sites oficiais, monografias, dissertações e textos legais disponíveis em bibliotecas físicas e virtuais, publicados no período de 1965 a 2017. A potencialidade de utilização racional do resíduo originado do processamento do maracujá na alimentação animal depende de conhecimentos sobre sua composição química-

\footnotetext{
${ }^{1}$ Possui graduação em Medicina Veterinária pela Universidade Federal Rural de Pernambuco (1984), mestrado em Zootecnia pela Universidade Federal Rural de Pernambuco (1990) e doutorado em Programa de Doutorado Integrado em Zootecnia pela Universidade Federal Rural de Pernambuco (2008).

${ }^{2}$ Possui graduação em zootecnia pela Universidade Federal de Alagoas (2018).

${ }^{3}$ Possui graduação em Zootecnia pela Universidade Federal de Alagoas (2019). Mestranda em Produção Animal pela Universidade Federal de Sergipe.

${ }^{4}$ Graduanda em Zootecnia pela Universidade Federal de Alagoas.

${ }^{5}$ Possui graduação em agronomia pela Universidade Federal de Alagoas (1974), mestrado em agronomia (Genética e Melhoramento de Plantas) pela Universidade de São Paulo, doutorado em agronomia (Genética e Melhoramento de Plantas) pela Universidade de São Paulo.

6 Possui graduação em Zootecnia pela Universidade Federal de Alagoas (2005), mestrado e doutorado em Zootecnia (Nutrição Animal) pela Universidade Federal Rural de Pernambuco (2007).

${ }^{7}$ Possui graduação em Arquitetura e Urbanismo pelo Centro Universitário CESMAC (2011), mestre em Dinâmica do Espaço Habilitado pela Universidade Federal de Alagoas (2015), doutoranda do Espaço Habilitado Pela Universidade Federal de Alagoas.

${ }^{8}$ Possui Graduação em Medicina Veterinária pela Universidade Federal Rural de Pernambuco (1985), Mestrado em Zootecnia pela Universidade Federal Rural de Pernambuco (1992), Doutorado em Zootecnia (2004) pela Universidade Federal da Paraíba e Pós-Doutorado(2015) pela Universidade Federal da Paraiba. Atualmente é professor Associado IV da Universidade Federal de Alagoas.
} 
bromatológica, da disponibilidade de seus nutrientes e do seu comportamento no trato gastrintestinal, bem como da avaliação do desempenho produtivo e econômico dos animais com eles alimentados. Quanto ao resíduo do biscoito é necessário ter conhecimento sobre os valores de digestibilidade da energia e nutrientes, sendo imprescindível para a realização de pesquisas com diferentes níveis de inclusão, que atendam às necessidades do animal em sua fase de vida. Para viabilidade e potencial de utilização de resíduos e coprodutos como alimentos para aves é necessário estudos sobre a caracterização, aplicação de métodos de tratamento, determinação de seu valor nutritivo, avaliação do desempenho produtivo e econômico dos animais, bem como sistemas de conservação, armazenagem e comercialização.

Palavras-chave: indústria alimentícia; aves industriais; resíduo do maracujá; resíduo da semente do maracujá. 


\section{INTRODUÇÃO}

As aves industriais têm sido foco de intensos estudos e pesquisas ao longo de décadas, servindo como modelo experimental para pesquisadores empenhados em garantir melhorias cada vez mais expressivas na produtividade, usando os conhecimentos de genética, nutrição, manejo, biossseguridade e economia e cujas aplicações vem propiciando avanços com respostas significativas na produção.

Neste sentido tem sido continua a avaliação de alimentos, comumente utilizados na avicultura, bem como com novos ingredientes considerados não convencionais, principalmente sobre $\mathrm{o}$ valor nutricional e utilização desses alimentos alternativos, em cada fase de criação, contribuindo com o conhecimento mais aprimorado sobre eles que permitem formular rações menos onerosas e mais eficientes, de forma a propiciar as aves a expressarem todo o seu potencial genético com maiores lucros para a avicultura mundial.

A busca por alimentos alternativos $\mathrm{e}$ de baixo valor comercial, como os resíduos da indústria alimentícia, representa uma forma de minimizar os gastos com alimentação. Porém, alguns fatores devem ser considerados na escolha de um material a ser utilizado na alimentação, tais como: a quantidade disponível; a proximidade entre a fonte produtora e o local de consumo; as suas características nutricionais; os custos de transporte e armazenagem (CÂNDIDO et al. 2008).

A Industria alimentícia tem gerado uma expressiva quantidade de resíduos que tem gerado grande preocupação de órgãos fiscalizadores quanto ao destino final desses resíduos, que comumente são depositados no meio ambiente, gerando problemas ambientais diversos. Com a indústria do biscoito não é diferente, gera uma grande quantidade de resíduos devido a inadequação no processo de produção e distribuição ao consumidor final, geralmente provenientes das perdas por quebras, excesso ou falta de cozimento durante o processamento, que podem ser considerados alternativas sustentáveis, quando utilizados na alimentação animal, incluindo, também, produtos não comercializados ou que ultrapassaram o prazo de validade (MORRETTO et al., 1999; OLIVEIRA， 2011; CORASSA, 2014).

A composição bromatológica do resíduo de panificação encontrada na literatura é muito ampla, devido à sua origem, seu armazenamento, seu processamento e à diversidade de ingredientes que entram em sua fabricação, e vem sendo testado, como substituto do milho na dieta, principalmente de 
ruminantes (AL-TULAIHAN et al., 2004;

FRANÇA, 2010).

O Comércio de suco de frutas no

Brasil tem atingido um expressivo crescimento, devido à grande variedade de frutas de sabores exóticos, que produz uma forte demanda no mercado, e a simplicidade dos processos de produção (FOLHAONLINE, 2005). Porém, o processamento das frutas também gera uma

\section{METODOLOGIA}

Trata-se de uma revisão de literatura tradicional, não sistemática, de caráter exploratório e qualitativo. Fez-se necessária leitura, análise e interpretação de livros,

\section{RESULTADOS E DISCUSSÃO}

A partir da análise dos documentos surgiram duas categorias temáticas: dieta de monogástricos com farelo da semente e casca de maracujá; valor nutricional e potencial de utilização do resíduo de biscoito na alimentação de monogástricos

\section{Dieta de monogástricos com farelo da semente e casca de maracujá}

O maracujá é uma fruta cultivada em quase todos os estados brasileiros, tendo o Brasil produzido, em 2016, 703.489 toneladas, sendo que a região Nordeste deteve $65 \%$ da produção nacional com 489.898 toneladas, na qual se destaca o grande quantidade de subprodutos, oriundos do tratamento industrial, que representam um grande potencial para alimentação animal. No ano de 2015 o Brasil produziu 1.453.610 toneladas de subprodutos de frutas (bagaço, caroço e pele) utilizados para a alimentação animal, das quais foram vendidas 1.205.803 toneladas, gerando 443.275 mil reais (IBGE, 2016).

periódicos, anais de eventos científicos, sites oficiais, monografias, dissertações e textos legais disponíveis em bibliotecas físicas e virtuais, publicados no período de 1965 a 2017.

estado da Bahia que é o maior produtor, com 342.780 toneladas, enquanto que o estado de Alagoas produziu 18.023 toneladas (Instituto Brasileiro de Geografia Estatística - IBGE, 2017), sendo a produção destinada, principalmente, para o processamento e produção de suco.

No processamento do maracujá, os principais subprodutos originados são as cascas e as sementes que correspondem ao percentual de 65 a $70 \%$ do peso do fruto (OLIVEIRA et al., 2002), gerando uma quantidade elevada desses resíduos que não são industrializadas e nem utilizados na alimentação humana (FACHINELLO, 2014). Em 2016 a produção no Brasil foi de 
492.928 toneladas de resíduos, sendo que 342.928 toneladas foram originadas da região Nordeste, das quais 12.616 toneladas foram produzidas no estado de Alagoas. Desta forma há consideráveis perdas de produtos durante $\mathrm{o}$ processamento do maracujá, e como este volume representa inúmeras toneladas, agregar valor a este resíduo é de interesse econômico, científico, tecnológico e ambiental (FERRARI et al., 2004).

Para Vieira et al. (2008) para que uma fonte alternativa de alimento seja de interesse do produtor, deverá existir em quantidades suficientes, constantes e a preços que compensem sua introdução nas formulações das dietas. Portanto, para a Introdução de uma nova fonte alimentar em um sistema de produção, deve-se levar em consideração tanto a sua qualidade nutricional, quanto a viabilidade econômica de sua utilização.

Assim sendo, a potencialidade de utilização racional do resíduo originado do processamento do maracujá na alimentação animal depende de conhecimentos sobre sua composição química-bromatológica, da disponibilidade de seus nutrientes e do seu comportamento no trato gastrintestinal, bem como da avaliação do desempenho produtivo e econômico dos animais com eles alimentados. Portanto, há a necessidade de se verificar o nível adequado e a viabilidade da utilização desses resíduos e quantificar as repostas produtivas e econômicas (PERONDONI, 2013). Segundo Mertens; Ely (1982) o desempenho animal depende da ingestão de nutrientes digestíveis e metabolizáveis, sendo que de $60 \%$ a $90 \%$ das diferenças de desempenho são causadas pelo aumento de ingestão e $10 \%$ a $40 \%$ das diferenças se referem à digestibilidade.

A composição química do resíduo do maracujá sofre variação segundo os métodos e eficiência do processamento, as variedades do maracujá utilizadas e as proporções de cascas e sementes contidas no material (PEREIRA et al., 2009).

As cascas de maracujá correspondem de $53 \%$ a $67 \%$ do fruto e foram objetos de várias pesquisas nos últimos anos (ABREU et al., 2009, COELHO et al., 2011), nas quais se observaram uma variação na sua composição bromatológica, mas apresentando um bom valor nutricional com valores de $11 \%$ a $13 \%$ de Matéria Seca (MS); 0,08\% a 6,86\% de Extrato Etéreo (EE); 0,92\% a 7,8\% de Matéria Mineral (MM); 0,3\% de Cálcio e 0,3\% de Fósforo (P); e ainda de $4,61 \%$ a $12,45 \%$ de Proteína Bruta (PB); 32,24 a 35,03\% de Fibra Bruta (FB); Fibra em Detergente Neutro (FDN) de 41,1\%; Fibra em Detergente Ácido de $34 \%$ (FDA) e para a Energia Bruta (EB) apresentam valores de $299 \mathrm{kcal} / \mathrm{kg}$ a $3655,57 \mathrm{kcal} / \mathrm{kg}$ (TOGASHI et al., 2008; 
OLIVEIRA et al., 2002; GONDIM et al., 2005; PEREIRA et al., 2009, FACHINELLO, 2014).

O uso das cascas tem sido feito na forma de silagem para serem utilizadas para animais ruminantes e as sementes podem sofrer um processo de secagem e moagem, e serem utilizadas como farelo na composição de rações, tanto para ruminantes quanto para não ruminantes, apesar do seu alto teor de fibras que podem limitar seu uso na alimentação animal, principalmente de monogástricos (LAVEZZO, 1995).

Já as sementes do maracujá representam cerca de $2 \%$ a $26 \%$ do peso total do fruto (NASCIMENTO, 2003, FERRARI et al., 2004, COELHO et al, 2011) e apresentam, assim como as cascas, uma variação de composição química de: $89,35 \%$ a $93,4 \%$ de Máteria Seca; $8,25 \%$ a $15,62 \%$ de Proteína Bruta; 52,01\% a 59,22\% de Fibra em Detergente Neutro; $43,71 \%$ a $49,5 \%$ de Fibra em Detergente Ácido; de 26,40\% a 64,80\% de Fibra Bruta; Celulose de 37,05\%; Hemicelulose de 2,77\% a 6,51\%; Lignina de 5,77\%; Pectina de 18,34\%; Carboidratos Totais de 58,53\% a 65,76\%; Carboidratos não Fibrosos 8,31\% a 1375\%; Polifenóis $\mathrm{mgEq} / \mathrm{g}$ de 4,01; Ácidos Graxos Saturados de 15,40\% Palmítico (C16) de 11,29\% e esteárico (C18) de 3,54\%; e Ácidos Graxos Insaturados de 84,60\% - Oléico (C18:1) de
19,53\%, Linoléico (C18:2) de 63,98\%, Linolênico (C18:3) de 0,40\%; 10,4\% de Nitrogênio Insolúvel em Detergente Ácido; $40,3 \%$ de Lignina; $18,84 \%$ a $28,9 \%$ de Extrato Etéreo; de $1,34 \%$ a $3,52 \% \%$ de Matéria Mineral e valores de Energia Bruta de $5.350 \mathrm{kcal} / \mathrm{kg}$ a $5.987 \mathrm{kcal} / \mathrm{kg}$, Cálcio de 0,06\% a 0,08\%; Fosforo Total de 0,31\% a 0,43\%; Fósforo Disponível de 0,14\% (FERRARI et al., 2004; PEREIRA et al., 2009; PERONDI, 2013; FACHINELLO, 2014; ZANETTI, 2015).

Com relação aos teores de aminoácidos da semente de maracujá, Perondi (2013) encontraram os seguintes valores para os aminoácidos essenciais: 1,39\% para a Arginina; $0,81 \%$ para a Fenilalanina; $0,21 \%$ para a Histidina; $0,32 \%$ para a Isoleucina; $0,28 \%$ para a Lisina; $0,11 \%$ para a Metionina; $0,38 \%$ para a Metionina + Cistina; $0,30 \%$ para a Treonina; $0,12 \%$ para o Triptofano e $0,49 \%$ para a Valina. Já para os aminoácidos não essenciais o autor encontrou valores de: 2,29\% para o ácido Glutâmico; 0,49\% para a Alanina; 0,51\% para a Gliciina; 0,61\% para a Leucina; 0,39\% para a Prolina; $0,52 \%$ para a Serina e $0,25 \%$ para a Tirosina.

Mesmo com essas qualidades, poucos estudos foram realizados para avaliar a inclusão do resíduo do processamento do maracujá na alimentação 
animal, principalmente na dieta de monogástricos.

Perondi (2013) e Fachinello (2014) realizaram experimentos visando avaliar $o$ valor nutricional do farelo da semente de maracujá na fase inicial de suínos, alimentados com dietas com diferentes níveis de inclusão do farelo e observaram valores de Energia Digestível de 3.244 $\mathrm{kcal} / \mathrm{kg}$ a $3.974 \mathrm{kcal} / \mathrm{kg}$ e coeficiente de digestibilidade da energia bruta de $60,64 \%$ a 71,36\%; de Energia Metabolizável de $3.223 \mathrm{kcal} / \mathrm{kg}$ a $3.583 \mathrm{kcal} / \mathrm{kg}$ e coeficiente de metabolizabilidade da energia bruta de $60,23 \%$ a $64,34 \%$; relação EM:ED obtida de 0,90; a Mátéria Seca Digestível foi de $52,92 \%$ a $62,39 \%$ e os coeficientes de digestibilidade da Matéria Seca foram de 59,23\% a 67,65\%; a Proteína Digestível foi de $8 \%$ a $9 \%$ com coeficiente de digestibilidade da proteína bruta de 70,54\% a 73,80\%; o Extrato Etéreo Digestível foi de $16,19 \%$ a $17,32 \%$ e os coeficientes de digestibilidade encontrado para o extrato etéreo foi de 83,23\% a 92,93\%; a Fibra em Detergente Neutro Digestível apresentou valores de $25,04 \%$ a $32,72 \%$ com coeficiente de digestibilidade de 49,86\% a 62,21\%; enquanto os valores da Fibra em Detergente Ácido Digestível foi de 19,60\% a $27,85 \%$ e o seu coeficiente de digestibilidade foi de $44,84 \%$ a $56,57 \%$.

Zanetti (2015) realizou ensaio de metabolizabilidade em frangos de corte com resíduo da semente de maracujá e encontrou valores de $3.954 \mathrm{kcal}$ de Energia Metabolizável Aparente (EMA)/kg e 3.945 kcal de Energia Metabolizável Aparente corrigida para Nitrogênio (EMAn)/kg; Coeficiente de metabolizabilidade da Matéria Seca de 66,92\%, da proteína Bruta de $63,38 \%$, da Fibra em Detergente Neutro de 50,41\%, da Fibra em Detergente Ácido de $30,53 \%$ e coeficiente de metabolizabilidade da EMAn de 69,34\%.

Ariki et al. (1977) realizaram estudos visando avaliar o efeito da utilização do resíduo da semente e de casca de maracujá na alimentação de frangos de corte sobre o desempenho animal e não observaram piora no desempenho, quando foi incluindo até $8 \%$ dos resíduos na dieta dos animais.

Resultados semelhantes foram observados por Togashi et al. (2008) que realizaram experimentos com frangos de corte objetivando avaliar o desempenho, características de carcaça dos animais, quando alimentados com rações compostas com níveis de $4 \%$ e $8 \%$ de inclusão de semente e de casca de maracujá separadas e verificaram que a inclusão de até $8 \%$ de sementes e de cascas de maracujá na dieta de frangos de corte não prejudicou o desempenho e nem o rendimento de carcaça de frangos aos 42 dias.

Perondi (2013), também, avaliou diferentes níveis de inclusão do farelo da 
semente de maracujá na dieta de suínos, na fase de crescimento e terminação, e não encontrou efeitos dos níveis sobre $\mathrm{o}$ desempenho dos animais, nem sobre a espessura de toucinho e profundidade de lombo, constatando que o farelo da semente de maracujá pode ser adicionado em até $16 \%$ em rações para suínos nestas fases, com possibilidade de redução de custos com alimentação.

Resultados semelhante foram obtidos por Fachinello (2014) que não verificou, também, efeito da inclusão do farelo da semente de maracujá na dieta de suínos sobre as variáveis de ganho de peso diário, consumo de ração, conversão alimentar, espessura de toucinho, profundidade de lombo. No entanto o farelo não se mostrou economicamente atrativo para os níveis de inclusão avaliados de 4\%, $8 \%, 12 \%$ e $16 \%$, de acordo com os preços vigentes no período experimental. Concluindo que o farelo da semente de maracujá pode ser adicionado em até 16\% em rações para suínos na fase inicial, sem influenciar o desempenho, as características quantitativas de carcaça e, economicamente dependerá do seu preço, assim como o dos demais ingredientes da ração.

Zanetti (2015) realizou experimento objetivando avaliar os efeitos da inclusão de níveis de $2,5 \%, 5,0 \%, 7,5 \%, 10,0 \%$ e $12,5 \%$ do resíduo da semente de maracujá na alimentação de poedeiras comerciais sobre o desempenho produtivo, qualidade de ovos e viabilidade econômica e concluiu que o resíduo de maracujá pode ser incluído na ração de poedeiras comerciais em até 7,5\% sem comprometer o desempenho e até 12,5 \% para a qualidade dos ovos. Já os níveis acima de $10 \%$ de inclusão do RSM mostraram-se economicamente viáveis.

Zanetti (2015), também, realizou experimentos com resíduo da semente de maracujá, em diferentes níveis $(2,5 \%$; $5,0 \% ; 7,5 \% ; 10,0 \%$ e $12,5 \%)$ na dieta de frangos de corte, e não observou efeitos dos níveis de inclusão do resíduo sobre as variáveis de ganho de peso e consumo de ração na fase de 1 a 21 dias e de 1 a 42 dias de idade, porém observou uma piora linear da conversão alimentar nos dois períodos avaliados. Concluindo que o resíduo de semente de maracujá no período de 1 a 21 e 1 a 42 dias de idade, pode ser utilizado em até $12,5 \%$ de inclusão nas rações de frangos de corte, sem prejuízo no rendimento de carcaça, e de até $7,5 \%$ sem prejuízos no desempenho e que níveis acima de 5,0\% de inclusão do resíduo da semente de maracujá mostraram-se economicamente viáveis.

Já Costa et al (2015) em experimentos com a utilização de resíduos de frutas na dieta de frangos de crescimento lento observaram que o consumo de ração, o ganho de peso e a conversão alimentar das aves alimentadas com resíduos não diferiu significativamente daquelas que receberam 
a ração controle. A substituição de $10 \%$ do milho por resíduos de abacaxi, caju ou maracujá nas rações não afeta o desempenho de frangos de corte de crescimento lento criados até 70 dias de idade.

Valor nutricional e potencial de utilização do resíduo de biscoito na alimentação de monogástricos

A indústria brasileira de biscoito e bolachas tem se destacado no cenário mundial ao longo dos anos, tendo atingindo a produção de 1.856 .602 toneladas em 2015, com valor de produção de 9.363.650 milhões de reais, tendo sido vendida 1.431.335 toneladas que geraram 7.318.560 milhões de reais (IBGE, 2016). Segundo ABIMAPI; NIELSEN (2017) o Brasil vendeu, no ano de 2016, 1.684,717 mil toneladas de biscoitos, o que gerou uma renda de 21,853 bilhões de reais, ocupando o quarto lugar em vendas no mercado mundial. Desse total de vendas brasileiras de biscoito, 128,586 mil toneladas foram do tipo wafer que gerou uma renda de 2,056 bilhões de reais.

Segundo Boggess et al. (2008), os resíduos da indústria de biscoitos apresentam valores de composição química variável, dependendo da fórmula e dos ingredientes utilizados, normalmente, possuem altos valores energéticos, por apresentarem elevados níveis de açúcares e gorduras, e conteúdo de proteína e lisina similares aos do milho, contudo, com valor de sódio mais alto.

Nesse sentido, ter conhecimento sobre os valores de digestibilidade da energia e nutrientes do resíduo do biscoito, torna-se imprescindível para a realização de pesquisas com diferentes níveis de inclusão, que atendam às necessidades do animal em sua fase de vida (BOSCOLO et al., 2004).

Corassa et al. (2014) em um trabalho de compilação de resultados de composição nutricional do farelo de biscoito de trabalhos publicados, nos anos de 2000 a 2011, encontraram valores de Matéria Seca de $85,0 \%$ a 97,37\%; valores de Proteína Bruta de 7,83\% a 11,06\%; valores de Extrato Etéreo de 5,25\% a 19,5\%; valores de Fibra Bruta de 0,5\% a 8,22\%; valores de Extrato Não Nitrogenado de 67,94\% a 71,38\%, valores de Matéria Mineral de 0,23\% a 6,2\%, valores de Cálcio de 0,01\% a $0,36 \%$; Valores de Fósforo Total de $0,1 \%$ a 0,5\%; Valores de Sódio de 0,19\% a $0,64 \%$ e valores de Energia Bruta que variaram de $3.200 \mathrm{kcal} / \mathrm{kg}$ a $4.485 \mathrm{kcal} / \mathrm{kg}$. Já Nunes et al. (2001) encontraram valores para Magnésio de 0,04\%; para o Potássio de 0,16\%; para o Sódio de 0,19\%; para o Ferro de 138,14 ppm; para o Cobre de 2,73ppm; para o Manganês de 12,22 ppm e para o Zinco 36,32 ppm.

Com relação aos teores de aminoácidos do resíduo de biscoito 
encontramos na literatura uma composição, também, variável: teores de lisina de $0,17 \%$ a $0,4 \%$; de lisina digestível de $0,17 \%$; teores de Metionina de $0,13 \%$; teores de Metionina mais Cistina de $0,26 \%$ a $0,37 \%$; teores de Metionina mais cistina Digestível de $0,26 \%$; teores de Treonina de $0,21 \%$ a 0,32\%; teores de Treonina Digestível de $0,22 \%$; teores de Triptofano de $0,07 \%$ a 0,11\%; teores de Triptofano Digestível de $0,08 \%$ de metionina (ROSTAGNO et al., 2011; CORASSA et al., 2014).

Rocha e Paternez (2014) em estudos sobre avaliação do teor de ácidos graxos trans em biscoitos wafer encontraram teores de gordura trans de 1,3 a 3,6 g por porção. Enquanto Aued-Pimentel et al. (2001) encontraram valores de ácidos graxos saturados mais trans de 7,85 a 18,33 g/100g nos diferentes tipos de biscoito wafer.

Volpato et al. (2014) realizaram experimentos para avaliar o valor nutricional do resíduo de biscoito salgado e doce para leitões e observaram valores de, respectivamente: $95,6 \%$ e $97,0 \%$ para o Coeficiente de Digestibilidade Aparente da Matéria Seca; $97,5 \%$ e $97,8 \%$ para o Coeficiente de Digestibilidade Aparente da Matéria Orgânica; 90,7\% e 93,4\% para o Coeficiente de Digestibilidade Aparente da Proteína Bruta; 94,0\% e 86,9\% Coeficiente de Digestibilidade Aparente da Energia Bruta e valores de $3.910 \mathrm{kcal} / \mathrm{kg}$ de Energia Digestível para o resíduo de biscoito doce e de $4.950 \mathrm{kcal} / \mathrm{kg}$ de Energia Digestível para o resíduo de biscoito salgado

Tardocchi et al. (2014), também, realizaram experimento objetivando avaliar a digestibilidade do resíduo do biscoito, sob a forma de farelo, para leitões na fase inicial e observaram valores de $3.849 \mathrm{kcal} / \mathrm{kg}$ de Energia Digestível na Matéria Seca; 3.558 $\mathrm{kcal} / \mathrm{kg}$ de Energia Digestível na Matéria Natural; $3.828 \quad \mathrm{kcal} / \mathrm{kg}$ de Energia Metabolizável Aparente na Matéria Seca; $3.537 \mathrm{kcal} / \mathrm{kg}$ de Energia Metabolizável Aparente na Matéria Natural; 95,17\% de Coeficiente de Digestibilidade da Energia Bruta.

Os valores de Energia Digestível do farelo de biscoito encontrados na literatura por Corassa et al. (2014) variaram de 3.220 $\mathrm{kcal} / \mathrm{kg}$ a $3.720 \mathrm{kcal} / \mathrm{kg}$, enquanto os valores de Energia metabolizável variaram de 3.185 $\mathrm{kcal} / \mathrm{kg}$ a $4.230 \mathrm{kcal} / \mathrm{kg}$.

Costa (2014) avaliando o valor nutricional do resíduo do biscoito doce e do biscoito de coco para tilapia-do-nilo encontraram valores, respectivos, de $32,22 \%$ e de $84,75 \%$ para o Coeficiente de Digestibilidade Aparente da Matéria Seca; $51,34 \%$ e $88,38 \%$ para Coeficiente de Digestibilidade Aparente da Proteína Bruta e de $45,94 \%$ a $86,44 \%$ Coeficiente de Digestibilidade Aparente da Energia Bruta. Com relação ao valor nutricional do resíduo de biscoito para frangos de corte Nunes et al. (2001) encontraram teores de 
energia metabolizável aparente (EMA) e energia metabolizável aparente corrigida pelo balanço de nitrogênio (EMAn) para o resíduo de biscoito de 4.480 e 4.339 $\mathrm{kcal} / \mathrm{kg}$, respectivamente.

Lima et al. (2012) conduziu ensaio de metabolismo com frangos caipiras e obtiveram níveis de EMA para o resíduo de biscoito polvilho salgado de $3.817 \mathrm{Kcal} / \mathrm{kg}$ e para o resíduo biscoito polvilho salgado + doce de $3.578 \mathrm{kcal} / \mathrm{kg}$.

Em experimentos de metabolizabilidade de nutrientes e energia dos resíduos de panificação em frangos de corte, Costa et al. (2015) obtiveram valores de energia metabolizável aparente (EMA) e energia metabolizável corrigida para nitrogênio, respectivamente, de 3959 $\pm 0,458$ $\mathrm{kcal} / \mathrm{kg}$ e $3480 \pm 0,399 \mathrm{kcal} / \mathrm{kg}$ para os resíduos de biscoito e bolacha, cujos valores de energia metabolizável para aves destes resíduos foram considerados superiores aos do milho.

Neste contexto observamos que os resultados de valor nutricional do resíduo de biscoito encontrados na literatura confimaram uma elevada contribuição energética, similar a dos grãos energéticos, por isso esses resíduos têm sido analisados para substituir parcialmente o milho em rações de animais não ruminantes (CORASSA et al., 2014).

Damron et al. (1965) avaliaram diferentes níveis de inclusão de resíduo de padaria $(0 \%, 2,5 \%, 7,5 \%$, e $10 \%)$ na alimentação de frangos de corte e não observaram diferenças significativas das dietas sobre o desempenho dos animais.

Em trabalho de pesquisa objetivando avaliar o efeito da substituição do milho pelo resíduo de panificação (biscoito) na dieta de frangos de corte, no período de 1 a 21 dias e de 21 a 42 dias de idade, Oliveira et al. (1995) observaram que o consumo de ração no primeiro período não foi afetado pelos níveis utilizados, mas que, no segundo período o consumo diminuiu com o aumento dos níveis de substituição.

No mesmo sentido, Boros et al. (2004) realizou ensaio de desempenho com a utilização de subprodutos de padaria, em dietas de frangos de corte, e observaram que o desempenho das aves não foi afetado pela inclusão de $10 \%$ desses resíduos na sua dieta.

No entanto, Al-Tulaihan et al. (2004) conduziram experimentos objetivando avaliar cinco níveis de inclusão $(05,5 \%, 10 \%, 20 \%$ e $30 \%$ ) de resíduo de padaria em dietas de frangos de corte e observaram que a inclusão de até 30\% do resíduo nas dietas não afetou negativamente o desempenho das aves.

Em experimento visando avaliar o efeito da adição de resíduo de padaria na dieta de frangos de corte Catalá-Gregori (2009) concluíram que até 7\% de inclusão do resíduo podem ser utilizados na dieta de 
frangos de corte sem prejudicar $\mathrm{o}$ desempenho dos animais.

Pereira (2010) realizou experimentos para analisar o efeito da substituição parcial do milho por resíduo de biscoito na ração de matrizes de marrecosde-pequim, sobre parâmetros de produção de ovos, conversão alimentar, peso das matrizes, ovos incubáveis, infertilidade dos ovos e morte prematura dos embriões, taxa de descarte dos ovos durante a incubação, taxa de eclosão e qualidade dos marrequinhos. A ração com a inclusão de $30 \%$ do resíduo de biscoito se mostrou superior a ração referência para a produção de ovos e conversão alimentar, não havendo diferenças para os outros parâmetros, concluindo que a ração com resíduo do biscoito pode diminuir o custo da ração e aumentar a renda bruta na produção de marrecos.

Já Al-Ruqaie et al. (2011) realizou estudos para avaliar o efeito da inclusão de níveis de $20 \%, 40 \%, 60 \%, 80 \%$ ou $100 \%$ do resíduo de panificação, em substituição ao milho, na dieta de frangos de corte não observaram diferenças significativas quanto ao ganho de peso, conversão alimentar, rendimento de carcaça, cortes e vísceras comestíveis e gordura abdominal, indicando a substituição total do milho pelo resíduo na dieta de frangos de corte até 35 dias de idade, com benefícios econômicos e sem prejuízo do desempenho animal.
Em suínos na fase de terminação Chamone (2011) realizou experimentos objetivando avaliar os efeitos de dietas contendo $0 \%, 5 \%, 10 \% 15 \%$ e $20 \%$ resíduo de bolacha sobre o desempenho, rendimento de carcaça e qualidade da carne concluiu que até o nível de $20 \%$ de inclusão não afeta o desempenho de suínos em terminação. Porém, afirmou que, para melhores resultados de qualidade de carcaça, a ração com $15 \%$ de resíduo de bolacha proporcionou os melhores resultados de rendimento.

Shahryar et al. (2012) também não encontraram diferenças para ganho de peso e conversão alimentar e características de carcaças de frangos alimentados com dietas contendo $0,8,16$ e $24 \%$ de uma mistura de resíduo de biscoito e bolachas.

No entanto, Adeyemo et al. (2013) realizou ensaio de desempenho com frangos de corte nas fases iniciais e finais de criação para avaliar o efeito de níveis de $0 \%, 25 \%$, $50 \% 75 \%$ e $100 \%$ de substituição do milho pelo resíduo de biscoito sobre o desempenho e observaram que o resíduo de biscoito pode ser usado como alimento para frangos de corte em níveis maiores de até $50 \%$ em substituição ao milho nas fases iniciais e finais de criação sem comprometer o desempenho e as características de carcaça dos frangos de corte. 
Já para leitões, Corassa et al. (2013) avaliaram o desempenho e viabilidade econômica de rações contendo 15 e $30 \%$ de resíduo de biscoito em suas dietas e constataram, em sua pesquisa, que não houve efeito dos tratamentos sobre o peso corporal dos leitões, consumo de ração e ganho de peso aos quatorze e vinte e um dias de avaliação. No entanto os leitões alimentados com dietas contendo $15 \%$ de farelo de biscoito apresentaram maior peso corporal e ganho de peso aos sete dias de avaliação e melhor conversão alimentar que a dieta controle no período total. Concluindo que dietas contendo 15 e $30 \%$ de inclusão de farelo de biscoito evidenciaram melhor viabilidade econômica, quando comparada com a dieta controle e que o farelo de biscoito pode ser utilizado em até $30 \%$ em dietas para leitões na fase inicial, sem prejuízos ao desempenho e à viabilidade econômica.

Em codornas de corte, Santos (2014) avaliou níveis de inclusão do resíduo do biscoito cream cracker em suas dietas sobre o desempenho produtivo e a viabilidade econômica e não observou efeito significativo dos diferentes níveis de inclusão sobre o consumo de ração, ganho de peso e conversão alimentar e nem sobre o rendimento de carcaça, cortes nobre, vísceras comestíveis e gordura abdominal no período de um a 42 dias de idade, concluindo que o resíduo pode ser incluído em até o nível de $20 \%$, sendo o seu uso economicamente viável na dieta para codornas destinadas a produção de carne.

Já Costa et al (2014) realizou experimentos sobre desempenho de alevinos recebendo níveis crescentes $(0,20$, 40, 60 e 80\%) do resíduo biscoito de coco em substituição ao milho da dieta, no qual foi avaliado a composição, os valores de peso final, consumo de dieta, ganho de peso, conversão alimentar aparente, taxa de crescimento específico, taxa de eficiência proteica e sobrevivência. As variáveis ganho de peso e taxa de retenção de proteína foram afetadas pelo tratamento com maior concentração do resíduo, assim como os valores da composição química da carcaça para extrato etéreo e matéria seca. $\mathrm{O}$ autor concluiu que o resíduo de biscoito de coco em substituição ao milho pode ser utilizado em até $60 \%$ em dietas para tilápia-do-nilo sem prejudicar o desempenho zootécnico e a composição química da carcaça.

Objetivando avaliar a inclusão de resíduo de biscoito em dietas de suínas em lactação, Corassa et al. (2014) realizou experimento com dietas contendo diferentes níveis de inclusão do resíduo $(0 \%$, $10 \%, 20 \%$ e $30 \%$ ) composto por $50 \%$ do tipo cream cracker e água e sal e $50 \%$ do tipo amanteigado, achocolatado. Os autores observaram que a massa, perda de massa e variação de massa das porcas, ao final da lactação, não diferiram, estatisticamente, 
entre os diferentes níveis de inclusão do farelo de biscoito, tendo concluído que os tratamentos não alteraram o consumo de ração, produção de leite, espessura de toucinho das porcas e desempenho da leitegada. Porém, também foi realizada a análise econômica que evidenciou melhores valores para as dietas contendo $20 \%$ e $30 \%$ de farelo de biscoito e indicaram a inclusão de farelo de biscoito em até $30 \%$, nas dietas para porcas em lactação.

\section{CONSIDERAÇÕES FINAIS}

Para viabilidade e potencial de utilização de resíduos e coprodutos como alimentos para aves é necessário estudos sobre a caracterização, aplicação de métodos de tratamento, determinação de

\section{REFERÊNCIAS}

ABREU, S. de P. M. et al. Características físico-químicas de cinco Genótipos de maracujazeiro-azedo cultivados no distrito federal. Revista Brasileira de Fruticultura, Jaboticabal - SP, v. 31, n. 2, p. 487-491, 2009.

ADEYEMO, G. O; ONI, O. R.; LONGE, O.G. Effect of Dietary Biscuit Waste on Performance and Carcass Characteristics of Broilers. Food Science and Quality Management. v.12, 2013.

Al-RUQAIE, I. M. et al. Performance, nutriente uitlization and carcass characteristics and economic impacto $f$ broiler chicken fed extruded bakery waste.
Shittu et al (2016) conduziu estudos objetivando avaliar da adição de 5\%, 10\% e $15 \%$ de níveis de resíduo do biscoito na dieta de frangos de corte sobre o desempenho, utilização de nutrientes e características de caraça e observaram que o resíduo do biscoito pode substituir até $15 \%$ do milho em dietas de frangos de corte nas fases iniciais e finais de criação sem efeito negativo sobre o desempenho, digestibilidade dos nutrientes e sobre as características de carcaça dos animais.

seu valor nutritivo, avaliação do desempenho produtivo e econômico dos animais, bem como sistemas de conservação, armazenagem e comercialização.

Journal of animal and veterinary advances. v.16, n.10, p.2061-2066, 2011.

AL-TULAIHAN et al. The Nutritional Evaluation of Locally Produced Dried Bakery Waste (DBW) in the Broiler Diets. Pakistan Journal of Nutrition, v.5, n.3, p.294-299, 2004.

ARIKI, J.; et al. Aproveitamento de cascas desidratadas e sementes de maracujá amarelo (Passiflora edulis J. Flavicarpa Deg.) na alimentação de frangos de corte. Científica, v.3, n.3, p.340-343, 1977.

BOGGESS, M., et al. Alternative feed ingredientes in Swine Diets. 2008.

Disponível

em: $<$ http://www.pork.org/filelibrary/Anim alScience/ Alternative\%20Feed\%20> 
Brochure.pdf $<$ Acesso em: 19 de Setembro de 2017.

BOROS, D. et al. Wheat by-products in poultry nutrition. Part II. Nutritive value of wheat screenings, bakery by-products and wheat mill run and their improved utilization by enzyme supplementation. Canadian Journal of Animal Science, v.3, n. 84, p.429-435, 2004.

BOSCOLO, W. R. et al. Digestibilidade aparente da energia e proteína das farinhas de resíduo da filetagem da Tilápia do Nilo (Oreochromis niloticus) e da Corvina (Plagioscisn squamosissimus) e farinha integral do Camarão Canela (Macrobrachium amazonicum) para a Tilápia do Nilo. Revista Brasileira de Zootecnia, Viçosa, v.33, n.1, p.8-13, 2004.

CÂNDIDO, M. J. D. et al. UTILIZAÇÃO DE COPRODUTOS DA MAMONA NA ALIMENTAÇÃO ANIMAL. In: III Congresso Brasileiro de mamona, energia e ricinoquímica, 2008, Salvador, Anais... Salvador, BA, 2008. Disponível em: https://www.alice.cnptia.embrapa.br/bitstre am/doc/939880/1/AACUtilizacaodesubpro dutos. Acessado em 02 de junho de 2017.

CATALÁ-GREGORI, P. et al. Inclusion of Dried Bakery Product in High Fat Broiler Diets: Effect on Pellet Quality, Performance, Nutrient Digestibility and Organ Weights. Asian-Aust. J. Anim. Sci. v. 22, n 5, p.686-693, 2009.

CHAMONE, J. M. A. Resíduo de bolacha em rações para suínos na fase de terminação. 2011.Dissertação (Mestrado em Zootecnia) - Programa de PósGraduação em Zootecnia, Universidade Estadual de Montes Claros-Janaúba. 2011. $53 \mathrm{p}$

COELHO, A. A.; CENCI, S. A.; ESENDE, E. D. de. Rendimento em suco e resíduos do maracujá em função do tamanho dos frutos em diferentes pontos de colheita para o armazenamento. Revista Brasileira de Produtos Agroindustriais, Campina Grande, v.13, n.1, p.55-63, 2011.

CORASSA, A. et al. Farelo de biscoito em rações para leitões na fase inicial. Comunicata Scientiae. v.4, n.3, p.231-237, 2013.

CORASSA, A. et al. Farelo de biscoito na alimentação de porcas em lactação.

Pesquisa Agropecuária Tropical. v.44, n.1, p.42-49, 2014.

COSTA, D. S. Resíduo da indústria alimentícia como substituto ao milho na dieta de tilápia-do-nilo. Dissertação (Mestrado em Ciências Ambientais). Universidade Estadual do Sudoeste da Bahia. 2014. 47p.

COSTA, M. N. F. da. et al. Desempenho de frangos de corte de crescimento lento alimentados com resíduos de frutas tropicais. In: Congresso Técnico Científico da Engenharia e da Agronomia CONTECC', 2015, Fortaleza, Anais.Fortaleza, CE, 2015. Disponível em: $<$ http://72soea.soea.org.br/anais/> Acessado em 02 de junho de 2017.

DAMRON, B.L., WALDROUP, P.W.; HARMS, R.H., Evaluation of dried bakery products for use in broiler diets. Poult. Sci., n. 63 p. $1122-1126.1965$.

FACHINELLO, M. C.; POZZA, P. C.; MOREIRA, I. Farelo da semente de maracujá na alimentação de suínos na fase inicial. Maringá, 2014. 64 p. Dissertação (Mestrado em Zootecnia) - Universidade Estadual de Maringá, Maringá, PR.

FERRARI, R. A., COLUSSI, F., AYUB, R. A. Caracterização de Subprodutos da Industrialização do Maracujá: Aproveitamento das Sementes. Revista Brasileira de Fruticultura, Jaboticabal SP, v.26, n.1, p.101-102, 2004. 
FOLHAONLINE. Coca-Cola confirma compra da Sucos Mais e acirra disputa com Del Valle. 2005. Disponível em: $<$ http://noticias.uol.com.br/economia/ultno t/valor>. Acesso em: 1 agosto, 2015.

FRANÇA, A.B. Resíduo de panificação na dieta de ovinos. 2010. Dissertação (Mestrado em Zootecnia) - Instituto de Zootecnia, Universidade Federal Rural do Rio de Janeiro, Rio de Janeiro, 2010. 49 p.

GONDIM, J.A.M.; et al. Composição centesimal e de minerais em cascas de frutas. Ciência e Tecnologia de Alimentos, Campinas, v.25, n.4, p.825-82, 2005.

\section{INSTITUTO BRASILEIRO DE} GEOGAFIA E ESTATÍSTICA. Produção Agrícola Municipal, 2016. Disponível em: $<$ https://ww2.ibge.gov.br/home/estatistica/ economia/pam/2015/default.shtm $>$. Acesso em: 27 de junho de 2017 .

LAVEZZO, O. E. N. M. Abacaxi, banana, caju, uva, maçã. In: SIMPÓSIO SOBRE NUTRIÇÃO DE BOVINOS,1995, Piracicaba. Anais. Piracicaba: FEALQ. 1995.p. 7-46.

MERTENS, D. R.; ELY, L. O.

Relationship of rate and extent of digestion to forage utilization: a dynamic model evaluation. Journal of Animal Science, Champaign, v.54, n.3/4, p. 895-905,1982.

MORETTO, E.; FETT, R. Processamento e análise de biscoito. São Paulo: Varela, 1999. 97p.

OLIVEIRA, E. L. et al. Digestibilidade e valor nutricional de alimentos energéticos para Tilápia (Oreochromis niloticus). In: CONGRESSO BRASILEIRO DE ZOOTECNIA, 2006, Recife. Anais... Recife: ABZ, 2006. Disponível em: http://www.abz.org.br. Acesso em: outubro, 2011
OLIVEIRA, L.F.; et al. Aproveitamento alternativo da casca do maracujá amarelo (Passiflora edulis f. flavicarpa Deg.) para produção de doce em calda. Ciência e Tecnologia de Alimentos, Campinas, v.22, n.3, p.259-262, 2002.

PEREIRA, G. C. Substituição parcial do milho da ração pelo resíduo da indústria de bolachas na produção de matrizes de marreco-de-pequim (Anas boschas). Monografia. (Graduação em Agronomia). Universidade Federal de Santa Catarina. 2010. 80 p.

PEREIRA, L. G. R. et al. Aproveitamento dos coprodutos da agroindústria processadora de suco e polpa de frutas para alimentação de ruminantes. Documentos. n. 220. Petrolina: Embrapa Semi-árido, 2009. 32 p. Disponível em: http://www.cpatsa.embrapa.br. Acessado em: 20 de maio de 2017.

PERONDI, D. Farelo da semente de maracujá na alimentação de suínos (30-90 $\mathrm{kg})$. 2013. 56 f. Dissertação (Mestrado em Zootecnia) - Curso de Pós-Graduação em zootecnia, Universidade Estadual de Maringá, Maringá, 2013.

ROCHA, G. G.; PATERNEZ, A. C. A. C. Avaliação do teor de ácidos graxos trans em biscoitos e avaliação do consumo por frequentadores de um supermercado de são Paulo. Rev. Simbio-Logias, v.6, n. 9, 2014.

ROSTAGNO, H.S. et al. Tabelas brasileiras para aves e suínos: composição de alimentos e exigências nutricionais. 3.ed. Viçosa:UFV,2011. 196p

SANTOS, J. S. Resíduo da indústria de biscoito: uma alternativa para alimentação de codornas. 2014. Dissertação ((Mestrado em Zootecnia) Universidade Federal de Alagoas. 2014. $35 \mathrm{p}$. 
SHAHRYAR, A; AHMADZADEH, H.; LOFTI, A. Possibilities of inclusion of Saccharomyces cerevisiae as replacement for fish meal or poultry meat by-product in broiler chicken diet. Journal of Biology Environmental Science, v.6, n.18, p.249251, 2012.

SHITTU, M.D. Replacement value of biscuit dough for maize on performance and nutrient utilization of broiler chickens. International Journal of Science, Environment and Technology, v. 5, n.03, p.1057-1065, 2016.

TARDOCCHI, C. F. T. et al.

Digestibilidade de resíduos agroindustriais para suínos na fase inicial. Revista Eletrônica Nutritime, [s. I.], v. 11, n.6, p.3770-3780, nov/dez. 2014.

TOGASHI, C. K.; et al. Subprodutos do maracujá em dietas para frangos de corte. Acta Scientiarum: Animal Sciences, Maringá, v.30, n.4, p.395-400, 2008.

VIEIRA, P. F. et al. Digestibilidade da matéria seca e proteína bruta do Resíduo seco de padaria em ovinos padaria em ovinos. ARS VETERINÁRIA, Jaboticabal, SP, V. 24, ARS VETERINÁRIA, Jaboticabal, SP, v.24, n.1. p.53 - 58, 2008.

VOLPATO, R. M. Coprodutos da agroindústria na alimentação de leitões.

Ciência Rural, Santa Maria, Online. 2014.

ZANETTI, L. R. Resíduo da semente de maracujá na alimentação de frangos de corte e poedeiras comerciais. 2015. Dissertação (Mestrado em Zootecnia) Universidade Estadual de Maringá, Maringá, 2015. 82p. 